\title{
A DEFENCE OF A RATIONALIST CONCEPTION OF PRACTICAL REASON*
}

\author{
GAL YEHEZKEL \\ The Sapir Academic College \& The Open University of Israel
}

\begin{abstract}
In this paper I attempt to refute the instrumental conception of practical reason, and thus defend a rationalist conception of practical reason. I argue that, far from merely playing an instrumental role, reason can be used by an agent to evaluate, that is, to approve or reject, final ends, which might be suggested by desires, and further to determine final ends independently of any desires, whether actual or potential, that the agent might have. My argument relies on an analysis of the concept of intention, and, more specifically, on the distinction between want and intention. I argue that the notion of an intentional action entails that reason can be used to evaluate and determine final ends.
\end{abstract}

Keywords: end, instrumental reason, intention, practical reason, reason

\section{Introduction}

Can agents rely on reason alone to determine their final ends? Can agents even use reason to evaluate the ends they set for themselves? According to an instrumental conception of practical reason, reason can only serve an instrumental role. That is, reason can only be used by an agent to determine means (or instrumental ends), but not to determine or evaluate their final ends. Thus, final ends, which are the things we pursue for their own sake, and terminate the chain of justification, cannot themselves be rationally justified. Hence this view is sometimes called "subjectivism" in order to emphasize the idea that practical reasons are agent-relative, as they are derived from the agent's own subjective, contingent, conative states.

The instrumental conception of practical reason is most famously attributed to David Hume. There is some controversy as to the specifics 
of Hume's position (see, for example, Hampton 1995; Weller 2013). However, my aim in this essay is not exegetic. I am concerned with the view that is expressed by the well-known quote from $A$ Treatise of Human Nature: "Reason is, and ought only to be the slave of the passions, and can never pretend to any other office than to serve and obey them" (Hume 1978, 415). My aim is to show that this view is false.

Here, by contrast, I intend to defend a rationalist conception of practical reason. I argue that, far from playing a merely instrumental role, reason can be used by an agent both to evaluate, that is, to approve or reject, final ends, which might be suggested by the agent's desires, and to further determine final ends independently of any desires, whether actual or potential, that the agent might have.

The strategy I employ involves exposing the shortcomings of its rival conception, that is, the instrumental conception of practical reason, mentioned above. Two (related) explanatory notes are in order. To begin with, I do not assume that instrumentalism and rationalism are the only two ways of conceiving practical reason. However, my criticism of the instrumental conception of practical reason inevitably leads to a rationalist conception of practical reason. Furthermore, it might be argued that my criticism is directed towards pure instrumentalism, that is, the view that reason can only be used in order to determine means to desired ends. There are however advocates of the Hume-inspired subjectivist school of thought who argue against pure instrumentalism, and maintain that reason serves a more complicated role than pure instrumentalism recognizes (see, for example, Schmidtz 2001; Reitsma 2013). Hence, it might be argued that arguments against pure instrumentalism do not refute the subjectivist school of thought. In response, I should note that I do not attempt to infer the rationalist view of practical reason from the falsehood of pure instrumentalism. Rather, pure instrumentalism, as a minimalist view of the role of reason, is the starting point of my analysis. In the course of my analysis, the true role of reason in practical reason is revealed, and a rationalist view is established.

Criticism of the instrumental conception of practical reason is not new (see, for example, Hampton 1998; Korsgaard 1998; Lebar 2004). However, there are many who believe that this criticism ultimately fails to disprove this view (see, for example, Hubin 2001; Andreou 2005; Spielthenner 2012; Markos 2014). Although I see merits in previous attempts to refute the instrumental conception of practical reason, in this paper I wish to advance a novel argument to this conclusion. I believe that my argument has the merit of not only refuting the instrumental conception of practical reason, but also of shedding light on the intricate relations between key concepts in practical reasoning, that is, desires, wants, intentions, actions, and ends.

Hence, in this essay I argue that we can use reason not only to evaluate 
ends that might be suggested by desires, but also to determine the final ends an agent should pursue independently of any desires that the agent might have, actual or potential. My argument does not rely on any contingent premises; for example, that individual agents (usually) have more than one end (Hampton 1998, 167). That is, I do not argue that it is only a matter of contingent fact that it is possible for reason to determine final ends. I argue that the notion of an intentional action entails that reason can be used both to evaluate and determine final ends. More specifically, I argue that the concept of intention entails a distinction between what is wanted and what is intended, and since reason is responsible for this distinction, it is the use of reason that enables an agent to determine his or her intentions and hence his or her ends.

I should stress that my aim in this paper is not to develop or defend a specific rationalist theory of practical reason (for example, that which forms the heart of Kant's moral theory). Hence, I do not attempt to identify any specific final ends that a rational agent should pursue.

Furthermore, rather than defending a rationalist conception of motivation, according to which reason alone can motivate actions, my interest is in defending a rationalist conception of practical reason. I argue that reason alone can be used to determine the final ends that an agent should pursue. Prima facie, it seems possible to integrate a Humean Theory of Motivation, according to which "reason alone can never be a motive to any action of the will" (Hume 1978, 413), with a rationalist conception of practical reason, according to which reason alone can be used to determine which final ends the agent should pursue (see, for example, Smith 1988). Although attempts to integrate these views have been criticized (see, for example, van Roojen 2002), in this essay I do not presume it to be impossible.

In section two I analyze the concept of intention. I focus on the relations between the concepts of intention, desire, want, action, and explore the role of reason in explaining the distinctions between these concepts. I show that the notion of intention, and hence the notion of an intentional action, relies on the distinction between a want and an intention. My main argument, which is developed in the following sections, is that this distinction, between what an agent wants and what he or she intends, relies on the use of reason to evaluate ends. In section three I discuss cases in which an agent has more than one end. Such cases have been used before in criticism of the instrumental conception of practical reason. However, my conclusion is that although instrumentalists must admit that the use of reason is necessary to explain the distinction between want and intention in these cases, they ultimately fail to disprove this view. Hence, in section four I turn my attention to a hypothetical case in which an agent has only one desire and only one end. I show that the distinction between a want and a desire is applicable to this case, and that this can only be explained by the use of reason. My analysis shows that 
the concept of intention entails that reason can be used to evaluate, that is, to approve or reject ends, which might be suggested by the agent's desires. In section five I argue that reason can not only evaluate ends that might be suggested by desires, but can also be used to determine ends that are not suggested by an agent's actual or even potential desires. Hence, reason has the authority to determine final ends altogether independently of desire. In section six I summarize the conclusions of my analysis.

\section{Terminology and the distinctions between desire, want, and intention}

I begin my discussion by analyzing the connections between the concepts of end, action, intention, want, and desire. This not only clarifies the connections between these concepts, but most importantly illuminates the differences between them.

Before turning to analyzing the relationships between these concepts, I concede that it is impossible to make a claim about them that has not yet been rejected in the literature. Nevertheless, there are claims that are generally agreed upon, and claims that are more controversial. In what follows I attempt to outline important distinctions between different aspects of human actions. First and foremost I argue that these conceptual distinctions exist and try to explain their importance. The terminology I use to describe these distinctions is of secondary importance. I try to use terms in accordance with their pre-theoretical use and defend the more contested choices of terminology I make. However, I do not expect my use of these terms to fully conform to their pre-theoretical use, or satisfy every theoretician. The most important aspect of my analysis is the distinctions that are represented by these terms, rather than the choice of terminology. Furthermore, my main focus in this analysis is the easier task of exposing conceptual distinctions, rather than conceptual ties. For in many cases a simple example can demonstrate the distinction between two concepts, while a claim for a connection of entailment, as a general connection, cannot be merely demonstrated and should always be argued for.

Let's begin by considering the following propositions:

(a) Naomi desires to eat ice cream.

(b) Naomi wants to eat ice cream.

(c) Naomi intends to eat ice cream.

(d) Naomi eats ice cream.

(e) Naomi's end is to eat ice cream.

Beginning with the concept of action, as expressed, for example, in (d), 
there are several distinctions that one can make. The first is between intentional and unintentional actions or mere behavior (Anscombe 1957, 84). Although one might doubt the existence of unintentional actions, for the present discussion it is unnecessary to enter into this debate, because our interest is in intentional actions, and what separates them from mere behavior. (Hence, from now on I will simply use the term "action" as an abbreviation for intentional action.) Furthermore, this essay assumes that an intentional action entails intention on the part of the agent (Davidson 1963; Chisholm 1964). This view has been criticized (for example, Anscombe 1957; Bratman 1984). However, I believe that the objections to this view have been sufficiently answered (Wasserman 2011). I should however stress that my argument does not assume the more controversial claim that for each thing a person does intentionally she intends it under the description used to attribute the intention. I merely assume that an intentional action requires the ability to intend to act, that is, if the concept of intention cannot be meaningfully attributed to an agent, it is meaningless to ascribe an intentional action to this agent.

Intention is always directed towards an action, which is supposed to bring about a wanted outcome, that is, an end. This is true both in cases in which that action is a final end and in cases in which it is only a means for bringing about another (perhaps final) end. Hence, an agent cannot intend to "world peace," but can intend to bring about world peace.

Some writers have made several distinctions between different categories of ends. By an "end" I simply mean a final end, that is, something we pursue for its own sake - our goal, rather than an instrumental end, a constitutive end, or a maieutic end (see Schmidtz 2001, 238-239). An end for an agent is something that the agent intends to bring about. Therefore, proposition (e) entails proposition (c). If the agent merely wants something, for example, "world peace," but does not intend to do anything to bring it about, it is not an end for this agent. (The converse does not hold true, however: proposition (c) does not entail proposition (e); not everything an agent intends to bring about is an end for him or her, and may only be a means to an end.)

Notice that even if one assumes that proposition (d), which describes an intentional action, implies the existence of an intention to eat ice cream (proposition (c)), the distinction between intentional action and intention is nevertheless maintained. This is because the converse obviously does not hold true. That is, the existence of an intention, as a mental attribute, does not entail the existence of an action, which is possibly a physical event that is supposed to be caused by that mental state. Thus, the possibility of an intention without an action ensures the conceptual distinction between intention and action. (Obviously I use the term intention in the sense of past intention and not in the sense of "intention in action" (Searle 1983, 83-98).) 
Intentional action hence entails the possibility of intention, and depends upon it. An analysis of the conceptual structure supporting intention is therefore necessary in order to understand the concept of an action. In what follows I focus on the distinction between intention and want, and examine the necessary conditions for maintaining this distinction.

However, before turning to the distinction between intention and want, I wish to clarify my use of the term "want," and the distinction I find important between "desire" and "want."

In proposition (a), eating ice cream is identified as something the agent desires. As previously mentioned, according to an instrumental conception of practical reason, reason can only be used by an agent in an instrumental role, while final ends are determined by desires. Obviously, in common use the term "desire" is too restrictive and narrow to explain all the final ends that agents have (Searle 2001, 167-170). Having a desire, in the sense of the term "desire" that follows this common usage, is just one way in which our final ends are determined by our desires or subjective contingent conative states. From now on I will use the term "desire" to indicate any subjective contingent conative state that can determine, at least according to the instrumental conception of practical reason, our final ends. Furthermore, these final ends are not subject to rational constraints, and, hence, are neither rational nor irrational. (My use of this term can perhaps be likened to what Hubin (1991) terms a "basic, unmotivated desire," in contrast to a "motivated desire".)

Since Naomi desires to eat ice cream, it is something that Naomi wants to do. Hence, proposition (a) entails proposition (b). A desire entails the existence of a 'want.' This, however, might be obscured by the fact that sometimes a desire is defeated, for example, by a stronger desire, and a matching want. In this case it might be the desire to keep one's figure. However, even if an agent decides not to satisfy a desire to eat ice cream, the want to eat ice cream still exists.

Obviously, Naomi might answer the question "Do you want to eat ice cream?" with the reply "No," but this is only the case if the question is interpreted as an offer of ice cream (for example, if a host is offering his or her guests ice cream for dessert). She might also answer the question, "I want to - actually I have been craving ice cream all day - but I also want to stick to my diet, so no thanks." This possibility shows that when we deny the existence of a want, where a desire clearly exists, we do so only in order to avoid a misunderstanding as to whether we are intending to act according to our want (see also Audi 1973, 7). The existence of a desire (a) therefore always entails the existence of a want (b), although this want can be defeated by a conflicting, stronger want.

The alleged connection between desire and want, that is, that desire (a) implies a want (b), may be contested, but I wish to stress that although it is clearly important to understand the correct relations between the basic 
concepts I am analyzing, the main argument of this paper does not rely on this claim. On the contrary, as I explain in what follows, I believe that if a desire (a) does not entail a want (b), this fact alone undermines the instrumental conception of practical reason, and in fact can be integrated with the main argument of this paper.

In order to understand why, let us begin by noting that even if a desire (a) does not entail a want (b), there are clear cases in which a desire does determine a want. This is evident from the meaningfulness of the claim "The baby wants to eat." The fact that a baby can be meaningfully said to want to eat shows that a desire can directly determine a want, because in this case it is clear that the baby's want is not determined by reason. Hence, if one insists that a desire (a) does not entail a want (b), one can only turn to reason in order to explain the possibility of a desire that is not accompanied by a matching want.

It might be objected that this possibility can be explained by conflicting desires. In this case, it might be argued, the stronger desire determines what the agent wants, while the weaker desire is dismissed. However, in order to relinquish his or her original want the agent must acknowledge this conflict, and this can only be explained by the use of reason. Hence, even according to this suggestion, only reason can determine our wants, and hence reason acts as a critic of desires. That is, reason can prevent desires from determining our wants. This conclusion implies that, contrary to the instrumental conception of practical reason, desire alone determines neither what we want, nor (as I argue in what follows) our intentions and our actions. Due to the fact that intentional actions are directed towards ends, if reason is used in order to determine our intentions, it is also used in order to determine our ends. Thus, the idea that a desire (a) does not entail a want (b) can be used to refute the instrumental conception of practical reason.

Again, I wish to stress that $I$ do not pursue this line of argument simply because I believe that a desire (a) does imply a matching want (b). I present this consideration in order to make clear that denying this implication does not disprove the conclusion of this paper.

Turning back to the relation between desiring and wanting, a basic difference between a desire and a want should be noted. A desire is nonrational, in the sense that it is meaningless to ask, "Why do you desire to eat ice cream?" It is always meaningful on the other hand to ask, "Why do you want to eat ice cream?" Although an answer to the latter question can be given by referring to a desire to eat ice cream, the question and the answer are not trivial, because it is possible that eating ice cream is merely a means to an end, and hence determined with the help of reason. This demonstrates the connection between reason and wanting.

The connection between reason and wanting does not imply that every want is determined by reason, as becomes evident when we observe the 
meaningfulness of the claim "The baby wants to eat." It does show, however, that we find a use in language for the term "want," as distinct from that of "desire," because of the possibility for a certain want to be determined by the use of reason, rather than by a desire. That is, the distinction between desiring and wanting is maintained by the fact that although a desire (a) entails a want (b), the converse does not hold true. An agent wants what he or she desires, but also wants things that he or she does not necessarily desire. This is possible in the case in which an agent wants something only as a means to an end. For example, even though Naomi hates the taste of ice cream and therefore has no desire to it eat, she may want to eat it, based on her dentist's recommendation to eat ice cream following a dental extraction. Reason, in this case, is used to determine means, which is not something which is governed by desire. The distinction between desire and want is therefore supported by the fact that the concept of a want is broader than the concept of a desire.

The logical distinction between desire (a) and want (b) therefore reflects the use of reason in determining means to final ends. In this use, reason must enable the agent to determine a want to bring about a means to an end, although there is no desire to bring about this means. So far the conclusions of our analysis are in accordance with the instrumental conception of practical reason. However, according to the instrumental conception of practical reason this is the only use of reason in practical reasoning. In order to see whether this view is correct let us now turn our attention to the distinction between want (b) and intention (c).

An agent's intention to perform an action, as described in proposition (c), entails that the agent 'wants' to perform this action, as described in proposition (b) (see also Schueler 1995, 35). Although some reject this claim, it is evident by the fact that it is always legitimate to ask "Why do you want to do it?" when an agent declares his or her intention to do something (Thompson 2008, 104).

Obviously the agent may not find any intrinsic value in a specific action, and only identify it as a means to a final end. However, if the agent intends to perform this action (even under threat), he or she nevertheless wants it to take place under these circumstances. There is obviously a sense in which an agent could consistently say that she intends to go to the dentist although she does not want to. However, what the agent would mean by this claim is that she does not want to go to the dentist in and of itself, but only wants to do it all things considered, that is, only as a means to stopping the pain she feels. It is of course possible to go to the dentist without wanting to do so. This is the case, for example, if I want to go an optometrist but have the wrong address, and end up at the dentist. However, in this case it would be false to say that I went to the dentist intentionally.

Although an intention (c) entails a want (b), the converse does not hold 
true. An agent may (desire and hence) want to eat ice cream, but not intend to eat ice cream, due to dietary restrictions. Hence, a want does not entail an intention to act according to the want. Reason can intervene, and the agent may therefore decide not to act on a certain want. The fact that proposition (b) does not entail proposition (c) therefore supports the distinction between the concept of want and the concept of intention.

Notice that the divergence between want and intention can only apply to what is wanted as a final end, and not to what is wanted as a means. It is possible, for example, for reason to intervene in a situation in which a desire determines a final end, while reason can exclude any intention to bring about the desired end (I discuss this possibility in detail below). A means, on the other hand, is determined by the use of reason. A means to a final end is only wanted if an agent intends to bring about the final end, and hence also intends to bring about the means to this end. An agent may want to eat ice cream, but if the agent decides not to eat it, and therefore not to buy it, he or she does not intend to take the money out of his or her pocket. The agent does not want to do this, since there is no reason to do so.

Obviously, the above reasoning is based on the premise that means can only be determined by the use of reason. This assumption is justified because determining that something is a means to an end inevitably relies on reason. Furthermore, we should remember that our previous analysis showed that the distinction between desire and want relies on the fact that reason can be used by an agent to determine a want for something that is not determined by desire.

The conclusion of the above analysis is that the concept of intention, and more specifically the distinction between want and intention, is based on the fact that a want does not entail an intention to act according to the want. I shall argue in what follows (section 4) that this distinction can only be explained by the use of reason to evaluate our ends.

\section{Reason, intention and the possibility of a multitude of ends}

In order to demonstrate the distinction between want and intention I relied on an example in which an agent (desires and hence) wants to eat ice cream, but not intends to eat ice cream, due to dietary restrictions. It natural to interpret this example as a case in which an agent has more than one end.

Interestingly, previous attempts to refute the instrumental conception of practical reason have also relied upon situations in which an agent has more than one end, in order to support the claim that reason is used in a more substantial role than that of simply determining the means to an end (see for example, Hampton 1998, 167; Korsgaard 1998, 216-7). 
Supporters of the instrumental conception of practical reason can, however, attempt to explain the distinction between want and intention by the possibility of an agent's having more than one desire, and hence more than one end. This can be explained as a situation in which one end, determined by desires, is put aside for the sake of another end, also determined by desires. This situation prima facie explains how it is possible for an agent to have a want (and a desire) for an end, while at the same time having no intention to pursue this end, thus explaining the distinction between want and intention, and hence the significance of the term "intention" itself.

Although I agree that the instrumental conception of practical reason fails to recognize that reason can be used to determine our ends, I do concede that the mere existence of a multitude of ends that an agent might have does not show that ends are susceptible to rational criticism. In what follows I explain why I believe that the mere multitude of ends that an agent might have ultimately fails to show that reason can be used by an agent to evaluate final ends, and hence fails to disprove the instrumental conception of practical reason.

To begin with, imagine a case in which there are two conflicting desires; for example, a desire to go to sleep and a desire to watch a film. The agent in this example wants both to go to sleep and to watch the movie, but cannot do both simultaneously. Hence, the agent must decide what to do. He prefers to watch the film, rather than going to sleep. He therefore watches the film, and later goes to sleep.

The previous scenario fails to explain the distinction between want and intention because it does not describe a case in which there is a want but no intention. The agent wants and intends to sleep (now), but will fulfil this intention only after the film ends. Notice also that according to this description of events (which for the moment I assume is coherent), reason is not used in order to intervene, and is not used by the agent to determine what he finally does. According to this description, the agent is pulled between two conflicting desires, and the stronger one prevails. Reason is not used in this scenario any more than in a case in which an agent is being pulled by two ropes in two different directions, and is forced by the pull of the ropes to move to the couch rather than to the bed.

According to the previous scenario, reason is not used to determine the action that the agent actually undertakes, which may make this example seem inappropriate for examining the use of reason in determining the intentions of an agent. However, its objective is to show that the distinction between want and intention cannot be explained by the multitude of ends per se, even if they conflict with one another, and that reason is not necessarily used in cases in which an agent has conflicting ends.

Let us now examine a second scenario, in which reason does intervene in 
determining which action the agent actually undertakes. This example will show that conflicting desires per se cannot explain the distinction between want and intention.

Consider the first scenario again, but with the following alteration. The agent wants to sleep much more than he wants to watch the film. However, after considering all the relevant information, the agent decides to watch the film, and to go to sleep later. His consideration is that the film is shown only rarely, and he is not likely to fall asleep while watching the film.

In the second scenario, reason is, in fact, being used to determine the agent's action, and to decide between conflicting desires. However, even in this case, I can see how someone might argue that there is no gap between want and intention. The agent, who wants to sleep (now), still intends to sleep (now). However, it might be argued that his intention is withheld, and will only be fulfilled following watching the film.

The previous examples show that the mere multitude of ends that an agent might have, even if they conflict, fail to show that reason is nothing more than a "slave of the passions." This explains why previous attempts to disprove the instrumental conception of practical reason, based on situations in which an agent has more than one end, have failed. This is reflected by the failure of these scenarios to describe a case in which want and intention differ.

In order to describe a situation in which there is a want but no intention, we must think of a situation in which there are reasons for abandoning any attempt to pursue a specific end. Obviously, it cannot be presumed in the present context that reason can be used to evaluate a final end - that would beg the question. It is, however, possible to demonstrate the divergence between want and intention even in the context of instrumental reasoning.

Consider, for example, a situation in which conflicting ends force an agent to completely give up pursuing an end she desires. In this case, the agent has no intention to bring about this end. For example, assume that Naomi wants to go both to Ruth's party and Sara's party. She realizes the she can't go to both parties, since she has no way of getting from Ruth's house to Sara's house, or vice versa, in time to participate in both parties. Naomi decides to go to Ruth's party, and although she wants to go to Sara's party, she has no intention to do so.

Notice that in this scenario, reason plays an indispensable role in explaining the gap between want and intention. Naomi might fail to realize that she has to choose between the two parties, and decide to go to Ruth's party first (because she wants to go there more) and to Sara's party later. If she fails to recognize (using reason) that she has to forfeit going to Sara's party, she does not give up her intention to go to Sara's party. Hence, only reason can explain the disparity between her want and her 
intention.

Since the previous example includes more than one end, and assuming that these ends are determined only by desire (any other assumption would obviously beg the question in the context of this discussion), it might be assumed to demonstrate that desire is responsible for explaining the disparity between want and intention. Thus, it may be admitted that the use of reason is necessary in order to explain the distinction between want and intention, since the recognition that two desires are in conflict, and that one should be discarded, is the conclusion of a reasoning process. However, it may further be claimed that the use of reason is not sufficient for explaining the divergence between want and intention, and that it is actually desire that cancels out the conflicting desire, thus explaining the possibility of a want without an intention.

I believe that this objection is the reason why previous attempts, which have relied merely on a multitude of (sometimes conflicting) final ends, have failed to refute the instrumental conception of practical reason. If this objection stands, it must be admitted that reason is not used in evaluating final ends, and is merely a 'slave of the passions.'

\section{Reason as a critic of ends}

So far I have argued that the mere possibility of an agent's having more than one end fails to disprove the instrumental conception of practical reason. In this section I turn my attention to an example in which an agent has only one desire, and only one end. In this case, supporters of the instrumental conception of practical reason cannot rely on conflicting desires in order to explain the distinction between want and intention. It is, rather, the use of reason itself that is responsible for rejecting an intention to bring about an end, which might be suggested by desire. Hence, intentional action relies on the use of reason by an agent in order to evaluate his or her suggested ends.

In order to acknowledge the use of reason as a critic of desires, imagine a case in which there is only one desire, that is, to go to Sara's party. Suppose that Naomi is too far from Sara's house to get to the party before it ends. Realizing that this is the case, Naomi gives up on going to the party. Obviously, she still wants to go, but she has no intention to go, because she knows that it is impossible for her to get there. Hence, participating in this event can no longer be described as her end.

This example shows us that ends are susceptible to rational criticism. An agent's ability to override the force of a specific desire by the use of reason does not depend on the force of another conflicting desire, but on the authority of reason. It is simply unreasonable to intend to realize an impossible end, and hence the use of reason enables an agent to reject a final end that might be suggested by desire. 
In answer to this example, it might be objected that this example fails to show that final ends are susceptible to rational criticism, because it relies on an implausible identification of an end. It might be argued that the desire to go to Sara's party is more plausibly a means for enjoyment, for example. However, rather than supporting the instrumental conception of practical reason, this objection undermines this view. For it relies on a notion of "plausibility" that obviously implies a rational evaluation of potential ends, which has no place in the confines of an instrumental conception of practical reason. It is hence impossible for a supporter of this view to reject this example based on an objection to the hypothetical end.

The examples given above involve situations in which reason is used to reject final ends, in order to explain the conceptual distinction between want and intention. However, the conclusion that follows from analyzing these examples also has implications for situations in which reason is used to approve ends that might be suggested by desires. The connection between intentions, ends, and reason is a conceptual connection rather than a contingent connection, and it holds for every intentional action on the part of an agent. If reason is used as the critic of desires, and determines the intention to act, it also enables an agent to determine whether or not to satisfy a desire.

In order to demonstrate this point, imagine, for example, that Naomi wrongly determines that she is too far from Sara's house to get to the party before it ends. Naomi therefore gives up her intention to go to the party, and, hence, it is not her end. Suppose however that Naomi later recognizes her mistake. She can, in fact, get to the party in time. As soon as she realizes this, she decides to go to the party, and thus determines attending the party as her end. Notice that nothing has changed in her desires, and therefore nothing in her desires can explain why attending the party suddenly became a final end for her. The only change was in her recognition that it is possible for her to reach the party. In this example it is clearly the use of reason that enables Naomi to determine going to the party as her final end.

Final ends are therefore not determined by desire alone, but by the use of reason (perhaps together with a desire). The use of reason enables an agent to decide whether to satisfy desire. Therefore, although in these situations desire suggests certain ends, it is reason that enables an agent to determine that a certain desire should be satisfied, and it is the use of reason that determines a certain state of affairs as a final end for an agent.

It might be objected that a Humean subjectivist can accommodate this example. Surely, it might be argued, he or she need not deny that unsatisfiable desires fail to generate practical reasons. In the subjectivist's view, a practical reason is generated by a basic desire, plus facts relevant to its satisfaction. In cases in which an agent has a basic desire, but there is - whether by necessity or by happenstance - absolutely no means for 
this desire's satisfaction (that is, no means to bring about its object), she has no practical reason to attempt to satisfy it. Hence, in forming no such intention, Naomi is showing her good sense, her virtuosity as a practical reasoner.

I believe that this objection misses the point of my argument. The fact that Naomi no longer intends to go to the party implies a change in her final end. As I have previously argued, an end for an agent is something that the agent intends to bring about. Therefore, if an agent does not intend to bring about something she wants, it is not an end for her. This is the reason why she has no practical reason to attempt to satisfy this desire. The object of this desire is not her end, and this can only be explained by the use of reason in order to evaluate final ends contrary to the instrumental conception of practical reason.

Another objection which might be raised at this point is that an instrumentalist may have an alternative explanation for the distinction between a want and an intention. Take the case of a single-desire agent who is irrational for not forming a corresponding intention. Why can't the instrumentalist simply say that an agent, when she does not form the intention to take the (presumably known) means to her only desired end, is simply means-end irrational? In such a case, this agent would seem to be guilty of a form of irrationality that (some versions of) instrumentalism can countenance. Accordingly, it is not necessary to appeal to a more "substantial" conception of reason to analyse this type of case.

However, this objection again undermines the instrumental conception of practical reason, rather than defends it. To begin with, it should be noted that it does not undermine the conclusion of the analysis of the previous example, according to which reason can be used in order to evaluate our ends. Furthermore, the claim that it is irrational of a single-desire agent to not form a corresponding intention implies that reason is used in order to determine intentions on the basis of wants - hence the failure is described as "irrationality" - and thus to determine the final ends of the agent, contrary to the instrumental conception of practical reason.

Finally, the previous examples focused on the possibility of attaining certain final ends, and may therefore give rise to the objection that they fail to show that reason can be used to evaluate and determine final ends. Although there is a sense in which it is justified to say that evaluating the possibility of achieving a certain end is an evaluation of this end, this seems to restrict the use of reason to its alleged instrumental function in determining means for ends. If, indeed, reason can be used to determine final ends, it could be expected that agents would be able to use reason to evaluate final ends as worth pursuing or not, in light of their intrinsic properties, rather than in light of the possibility of attaining these ends.

In response to this objection it is easy to show that reason can be used to 
evaluate final ends as rational or irrational in light of their intrinsic properties. For example, suppose that Naomi decides to pursue her childhood dream of becoming a hairdresser and moving to a small village, where she will cut the hair of all those, and only those, inhabitants of the village who do not cut their own hair. She soon realizes this end is self-contradictory. A rational agent cannot adopt a selfcontradictory scenario as his or her end, and realizing this, the agent decides to abandon the original intention to pursue his or her dream. Obviously, in this example it is also impossible to attain the end that the agent wants to pursue. However, the impossibility of attaining this end is due to the contradictory nature of the final end, which is recognized by the use of reason. The intrinsic properties of this end, rather than the mere nomological impossibility of attaining it, or a conflicting desire, therefore make it unreasonable as a final end.

Again, it might be objected that this example relies on an implausible identification of an end. However, as I have pointed out before, this objection undermines, rather than supports, the instrumental conception of practical reason. For it relies on a rational evaluation of potential ends, which has no place in the instrumental conception of practical reason. In fact, it is exactly my aim in this analysis - to show that ends are susceptible to rational evaluation.

In conclusion, the use of reason is a necessary and sufficient condition for explaining the distinction between want and intention. Reason is thus necessary for explaining the significance of the term "intention" and hence for explaining the possibility of an intentional action. It is the use of reason that enables an agent to determine his or her intentions, and hence her or her ends.

This conclusion explains why the existence of a desire for something (a) does not entail that the agent's desire is his or her end (e). Again, the mere number of desires, even if they are conflicting, cannot explain this distinction. A subject may not be aware of the fact that he or she has enough money, for example, to buy only ice cream or only chocolate. Only when the agent understands this does she dismiss the end of eating ice cream.

Hence, when used by an agent to determine his or her intentions, reason can be used either to approve or to reject his or her final ends, which might be suggested, rather than determined, by desires. According to the conclusion of the previous analysis, desires do not determine final ends, but only suggest final ends. If reason is used to determine intentions, it is also used to determine ends, which might be suggested by desires, which only then become an end for an agent. 


\section{Reason and the determination of ends}

The previous section concluded with the understanding that it is reason that is used by agents to determine their final ends, rather than desire. Even if desire suggests these ends, it is ultimately the function of reason to approve or to reject these potential ends. My argument so far shows that reason can reject or approve ends. It might however be argued that this still does not give reason a sufficiently significant role. For a rationalist conception of practical reason implies that reason can be used to determine which ends are worth pursuing (and which are not).

In this section I will argue that reason can not only be used to evaluate final ends that might be suggested by desires, but can also determine final ends independently of desires altogether. I should stress that I do not merely argue that reason can determine ends that are not suggested by actual desires, but that reason can determine ends that are not suggested by anticipated desires. Rather, I argue that reason can determine final ends that are altogether independent of the agent's desire, whether actual or potential.

Defending this possibility is of great importance. Although the above analysis showed that reason can be used to determine final ends, the objection might be raised that it falls short of defending a rationalist conception of practical reason, as long as it is not shown that reason can be used to determine final ends that are not suggested by desires, whether actual or potential. Furthermore, if reason can be used in determining final ends, we might expect reason to also be used to determine final ends independently of an agent's desires.

A decisive reply to this concern is difficult to provide within the scope of this paper, since it requires giving an example in which reason can be used to determine a final end for an agent, without relying on any existing, or even possible, desire. This demand is equivalent to developing a full-blown rationalist theory of practical reason, which is beyond the scope of this paper. In the present context, I only attempt to defend the possibility of constructing such a theory. That is, I argue that reason can be used to determine final ends, but I do not argue that is actually does - a claim which obviously requires the identification of these ends. In what follows I explain how such a theory can be constructed.

To begin with, the previous example shows that it is possible to evaluate ends as rational or irrational independent of any desire. Naomi the hairdresser does not need to have any desire to fulfill her plan in order to realize that it is irrational to attempt to bring it about. All she needs to do is to consider this possibility.

Furthermore, suppose that reason can be used to determine that a rational agent should avoid certain states of affairs. This is not the case in the 
previous example of Naomi's wish, because her end is self-contradictory, and therefore there is no need to attempt to avoid this alleged state of affairs. However, if reason can be used to determine that a rational agent should avoid certain possible states of affairs, it would follow that reason could ipso facto be used to determine which states of affairs (final ends) the agent should pursue.

It might be claimed that in this case reason is not used to determine a specific end, but rather to determine a class of states of affairs that the agent could rationally pursue. In answer to this argument it should first be noted that determining a final end always involves determining a class of states of affairs that the agent attempts to bring about. This is due to the fact that a state of affairs can be defined with the help of indefinite distinctions, and therefore can always be described more specifically or more generally. Thus, if an agent decides to eat ice cream, there is an indefinite number of events that would fulfill his or her intention. For example, he or she can eat vanilla or chocolate ice cream, from a cone or a dish, bought from an ice cream parlor or from an ice cream stand, and so on.

Furthermore, determining a state of affairs as an end for an agent is the same as determining a class of possible worlds that the agent should pursue; the agent should attempt to realize a member of the class. This is equivalent to determining that all other possible worlds, that is, those in which the agent does not eat ice cream, should be avoided (rather than brought about). The same end (for example, eating ice cream,) can be described negatively, as avoiding not eating ice cream.

Thus, determining which states of affairs should be avoided is equivalent to determining which states of affairs an agent should pursue. If it is possible to determine which states of affairs should be avoided, it is therefore also possible to determine which ones should be pursued.

An example of an attempt to develop and demonstrate this kind of rationalist theory of practical reason is found in Kant's moral theory (1996). Kant's theory is based on the categorical imperative, as a rational restriction on the ends and actions of any rational agent. This demands that the agent act only in accordance with that maxim that he or she can, at the same time, will to become a universal law. Ipso facto, it also supposedly determines a final end, that is, humanity, for any rational agent.

Obviously, I do not argue that Kant's theory is true. I do argue, however, that his strategy for developing a rational theory of practical reason is coherent. If this is correct, reason can be used to determine final ends, independently of desires altogether. 


\section{Conclusions}

The starting point of my analysis was the use of reason by an agent in determining and evaluating the means for achieving certain ends, which might be suggested by an agent's desires. This is in accordance with the instrumental conception of practical reason, which denies that reason can be used in evaluating or determining final ends. However, contrary to the instrumental conception of practical reason, my analysis shows that reason can be used by an agent to evaluate, that is, to approve or reject, final ends that might be suggested by desires. This possibility is implied by the notion of intention, and hence is required in order to explain the nature of intentional action. Furthermore, my analysis shows that reason can be used to determine final ends independently of any desire, whether actual or potential.

The instrumental conception of practical reason is therefore inadequate, and should be replaced with a rationalist conception of practical reason, according to which reason alone can be used by an agent to determine which final ends he or she should pursue. Although I have not attempted to develop and defend a full-blown rationalist theory of practical reason, including principles of conduct that any rational agent should follow, I trust that the possibility of constructing such a theory has been sufficiently established.

\section{REFERENCES}

Andreou, C. 2005. The Voices of Reason. American Philosophical Quarterly. 42: 33-45.

Anscombe, G. E. M. 1957. Intention. Oxford: Basil Blackwell.

Audi, R. 1973. The Concept of Wanting. Philosophical Studies 24: 1-21.

Bratman, M. 1984. Two Faces of Intention. Philosophical Review 93: 375-405.

Chisholm, R. 1964. The Descriptive Element in the Concept of Action. Journal of Philosophy 61: 613-625.

Davidson, D. 1963. Actions, Reasons, and Causes. The Journal of Philosophy 60: 685-700.

Hampton, J. E. 1995. Does Hume have an instrumental conception of practical reason? Hume Studies 21: 57-74.

Hampton, J. E. 1998. The Authority of Reason. Ed. R. Healey. Cambridge: Cambridge University Press. 
Hubin, D. C. 1991. Irrational Desires. Philosophical Studies 62: 23-44.

Hubin, D. C. 2001. The Groundless Normativity of Instrumental Rationality. The Journal of Philosophy 98: 445-468.

Hume, D. 1978. A Treatise of Human Nature. Ed. L. A. Selby-Bigge. Oxford: Oxford University Press.

Kant, I. 1996. Critique of Practical Reason. In Practical Philosophy, ed. M. J. Gregor, 133-271. Cambridge: Cambridge University Press.

Korsgaard C. M. 1998. The Normativity of Instrumental Reason. In Ethics and Practical Reason, ed. G. Cullity and B. Gaut , 21554. Oxford: Clarendon Press.

Lebar, M. 2004. Ends. Social Theory and Practice 30: 507-533.

Markos, V. 2014. Instrumental Rationality. European Journal of Philosophy 22: 443-462.

Reitsma, R. L. 2013. How a Modern-day Hume Can Reject a Desire Categorically: A Perplexity and a Theoretically Modest Proposal. European journal of analytic philosophy 9: 48-66.

Schmidtz, D. 2001. Choosing ends. In Varieties of practical reasoning, ed. E. Millgram, 237-257. Cambridge, Ma.: The MIT Press.

Schueler, G. F. 1995. Desire: Its Role in Practical Reason and the Explanation of Action. Cambridge, MA.: MIT Press.

Searle, R. J. 1983. Intentionality: An Essay in the Philosophy of Mind. New York: Cambridge University Press.

Searle, R. J. 2001. Rationality in Action. Cambridge, MA.: MIT Press.

Smith, M. 1988. Reason and Desire. Proceedings of the Aristotelian Society 88: 243-258.

Spielthenner, G. 2012. Justificatory Reasons for Action. European Journal of Analytic Philosophy 8: 56-72.

Thompson, M. 2008. Life and Action: Elementary Structures of Practice and Practical Thought. Cambridge, MA.: Harvard University Press.

Van Roojen, M. 2002. Should Motivational Humeans be Humeans About Rationality? Topoi 21: 209-215.

Wasserman, R. 2011. Intentional Action and the Unintentional Fallacy. Pacific Philosophical Quarterly 92: 524-534.

Weller, C. 2013. Hume on the Normativity of Practical Reasons. Hume Studies 39: 3-35. 
EuJAP | Vol. 13, No. 1, 2017 